\title{
El retrato de Garfio como Vengador Obsesivo en Peter Pan: Un acercamiento desde la comunicación verbal y no verbal
}

\section{Garfioren irudikapena Mendekatzaile Obsesibo moduan Peter Pan-en: Hurbilpen bat, hitzezko eta hitzik gabeko komunikaziotik}

\section{The portrait of Hook as an Obsessive Avenger in Peter Pan: An approach from verbal and nonverbal communication}

\section{Laura Sanz-Simón ${ }^{1}$}

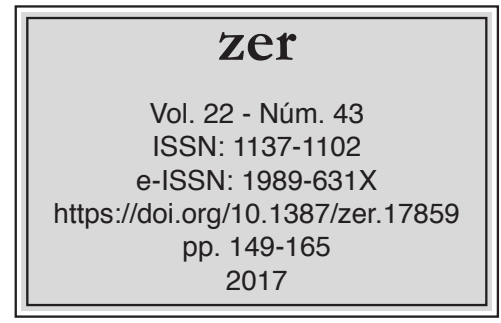

Recibido el 16 de mayo de 2017, aceptado el 16 de octubre de 2017.

\begin{abstract}
Resumen
La existencia de estereotipos relacionados con la discapacidad en el cine es evidente. Pero, puesto que la mayoría de los estudios son intuitivos, hay que preguntarse de qué manera son percibidos los personajes para clasificarlos así. Esta investigación pretende probar que la comunicación verbal y la no verbal son herramientas esenciales en la percepción de estereotipos. Los resultados del análisis del personaje Garfio (Peter Pan), junto con las opiniones de 100 niños encuestados, han desvelado que estos procesos engloban la mayor cantidad de información que procesamos. Por ello, resulta fundamental prestarles atención a la hora de crear personajes.
\end{abstract}

Palabras clave: Cine, discapacidad, estereotipos, comunicación, infancia, educación.

\section{Laburpena}

Zineman ere desgaitasunarekin lotutako estereotipoak badirela begien bistakoa da. Baina, azterlan gehienak intuitiboak direnez, geure buruari galdetu behar diogu ea nola hautematen ditugun pertsonaiak, halakotzat hartuak izan daitezen. Ikerlan honen helburua da, hain zuzen,

1 Universidad Rey Juan Carlos, laura.sanz.simon@urjc.es 
frogatzea hitzezko komunikazioa eta hitzik gabekoa funtsezkoak direla estereotipoen pertzepzioan. Peter Pan laneko Garfio pertsonaia aztertu eta 100 haurren iritzia bildu dugu inkesta baten bidez, eta azterlanaren emaitzek argi erakusten dute prozesatzen dugun informaziotik gehiena prozesu horietan biltzen dela. Horrenbestez, guztiz funtsezkoa da haiei adi egotea pertsonaiak sortzeko unean.

Gako-hitzak: Zinema, desgaitasuna, estereotipoak, komunikazioa, haurtzaroa, hezkuntza.

\begin{abstract}
The existence of stereotypes about disability in movies is evident. As most studies are intuitive, it is necessary to ask how characters are perceived to classify them in this way. This investigation try to check that verbal and nonverbal communication are essential tools in the perception of stereotypes. The results of the analysis of the character Hook (Peter Pan), along the views of 100 children surveyed, have revealed that these processes includes the biggest amount of the information we process. Thus, it is fundamental to pay attention to them when creating characters.
\end{abstract}

Keywords: Cinema, disability, stereotypes, communication, childhood, education. 


\section{Introducción}

El cine representa la realidad de la sociedad. Y la discapacidad forma parte de esa realidad (Badia, 2010). Por ello, desde sus inicios, los profesionales del medio introdujeron personajes con discapacidad en los filmes (Aparicio \& Gómez-Vela, 2010). Podríamos pensar que es una buena noticia, pero debemos pararnos a pensar si esto se hizo de la forma más adecuada. Y es que, también desde el principio, el séptimo arte llenó las pantallas de estereotipos que distorsionaron la imagen de la discapacidad (Monjas, Arranz \& Rueda, 2005; Black \& Pretes, 2007; Aparicio \& Jordán de Urríes, 2014) y que aún hoy perduran (Norden, 2014; Badia \& Sánchez-Guijo, 2010; Longmore, 2003). Tal y como señala Alegre (2003: 190):

La historia de la discapacidad en el cine es la larga historia de una distorsión de la imagen según los intereses económicos, políticos o sociales de la época, presentando el punto de vista del no discapacitado y excluyendo el de la persona con discapacidad.

Ya fuera por desconocimiento o por las posibilidades que la discapacidad ofrecía, muchos cineastas optaron por utilizarla para causar determinados efectos en el público. Así, a lo largo del tiempo, numerosos personajes con discapacidad han provocado desde sensación de peligro, miedo y angustia hasta tristeza, compasión e, incluso, ternura. No debemos olvidar que, aunque ahora disponemos de una gran cantidad de información, antes, las personas que no conocían directamente a una persona con discapacidad tendían a creer lo que veían en las películas y, por ende, a pensar que las personas con discapacidad eran seres grotescos y despiadados, individuos torpes y graciosos o criaturas vulnerables que no podían valerse por sí mismas, enamorarse o vivir una vida plena y feliz.

Uno de los estereotipos más habituales, vinculado a la discapacidad física, es el Vengador Obsesivo, término acuñado por el profesor Martin F. Norden. Casi siempre varón, el Vengador Obsesivo es cruel, violento y sanguinario; un personaje amargado y despiadado que solo piensa en vengarse, bien para castigar a los responsables de su discapacidad, bien como consecuencia de actos que él considera inmorales (Norden, 1998). Son muchas las películas que, a lo largo de la historia, han utilizado este estereotipo para mostrar a sus personajes con discapacidad física. Constituyen algunos de los ejemplos que encontramos Grekko (The Path of Hapiness, 1916), el Capitán Garfio (Peter Pan, 1924), el Capitán Ahab (The Sea Beast, 1926), el Duque Cathos de Alvia (Drums of Love, 1928), Malita (The Devil Doll, 1936), [de nuevo] el Capitán Ahab (Moby Dick, 1956), Alex (Cutter's Way, 1981) y [nuevamente] el Capitán Garfio (Hook, 1991).

Diversos estudios (Norden, 1998; Alegre, 2003; Solaz, 2004; Norden, 2007; Sanz, 2014; Sutton, 2014) coinciden en señalar que el estereotipo existe y en que proporciona una mala imagen de la discapacidad física. Sin embargo, en ellos no se encuentra un análisis sistemático que permita comprobar lo que aseveran. Tenemos que presuponer, entonces, que estos estudios son intuitivos. Pero hay que preguntar- 
se qué determina que los personajes que mencionan se encuadren dentro del estereotipo del Vengador Obsesivo; en qué se apoyan (específicamente) otros autores para clasificarlos así.

La mayoría de los rasgos de los personajes, malvados o no, del cine pueden estudiarse a través de sus palabras, sus gestos, sus expresiones faciales, los tonos de su voz... Dichos aspectos comprenden la comunicación verbal y la comunicación no verbal de los personajes. Estos dos procesos pueden ser, pues, los que nos descubran el modo en que llegamos a categorizar y encasillar a los personajes en un estereotipo concreto. Y, aunque siempre es importante mostrar la realidad de forma acertada, lo es más, si cabe, en los filmes destinados al público infantil. Dado que los niños constituyen un público más sensible a todo aquello a lo que se exponen (Chacón, 2005), los cineastas han de cuidar lo que les muestran y la forma en que lo hacen.

Por todo esto, el objetivo de este estudio consiste en investigar de qué modo se percibe un personaje de dibujos animados con una discapacidad física como es Garfio (Peter Pan, 1953) a través de dos herramientas de análisis fundamentales: la comunicación verbal y la comunicación no verbal (en este caso, dejamos a un lado las características cinematográficas como el color o el encuadre). Ahondar en los aspectos que señalan al personaje seleccionado como un Vengador Obsesivo puede ayudar a ver qué transmitimos a los niños y cómo procesan ellos la información.

Como buen Vengador Obsesivo, el capitán Garfio se nos presenta como un personaje vengativo, con malas intenciones y al que no le importa en absoluto hacer sufrir a los demás. Su deseo de venganza es tal que todos sus pensamientos, palabras y acciones están destinados a cumplir con el cometido que él mismo se ha impuesto y que lo atormenta: atrapar y matar a Peter Pan. Sin embargo, el Vengador Obsesivo no suele tener mucha suerte; sus malévolos deseos y su mal hacer acaban conduciéndolo irremediablemente hacia la muerte o, como en este caso, puesto que es una película infantil, hacia sus peores temores (representados en la figura del cocodrilo).

La hipótesis principal de la investigación es que Disney recrea a Garfio como un Vengador Obsesivo a través de la comunicación verbal y no verbal. Esta hipótesis se centra, por tanto, en aportar argumentos que lleven a probar que el pirata protagonista puede integrarse en la mencionada categoría. Además, se ha formulado una hipótesis específica que recoge otros aspectos importantes del personaje: Garfio no es el prototipo de villano, pues algunos rasgos de su personalidad hacen que no infunda temor y proporcionan al personaje una vis cómica.

Para realizar esta investigación, en primer lugar, se ha llevado a cabo un análisis descriptivo de las escenas en las que aparece Garfio basado en la recogida de los datos que atañen a la comunicación verbal y no verbal del personaje. En segundo lugar, se ha seleccionado una muestra homogénea de niños a los que se ha entregado una encuesta acerca del pirata de Disney. En ambos casos, los resultados obtenidos han sido cuantificados.

\section{Metodología}

En esta investigación no solo se observa cómo es Garfio en la realidad fílmica, sino que también se tiene en cuenta cómo lo perciben los niños. De este modo, las hipótesis se abordaron de forma dual: por un lado, diseccionando los rasgos del personaje; 
por otro, a través de las opiniones que este genera en los niños. Aunque los resultados extraídos de uno y otro punto están orientados a comprobar la veracidad de las dos hipótesis y sus respectivas variables, debido a la corta edad de los niños a los que se remitió el cuestionario, no hay un elevado número de preguntas y estas están formuladas de manera sencilla para favorecer su comprensión.

En primer lugar, se efectuó la recogida de los datos concernientes a la comunicación verbal y no verbal de todas las escenas de la película en las que aparece Garfio o que hacen referencia a él. Dichos datos fueron analizados de forma sistemática con ayuda de unas tablas que reflejaban, por cada una de las variables de las hipótesis general y específica, las características verbales (oraciones) y no verbales (gestos, expresiones faciales, tonos de voz...) que definen al personaje y cuántas veces se encuentran dichas características a lo largo del filme (método cuantitativo). Después, tomando como base los resultados de las tablas, se redactaron unos análisis descriptivos en los que se incluyó algún ejemplo tomado de la recogida de datos.

En segundo lugar, se buscó una muestra homogénea y coherente de niños y niñas pertenecientes a un entorno urbano concreto; en este caso, todos los participantes residen en la capital madrileña, pero no acuden al mismo centro educativo. Se solicitó (además de que hubieran visto Peter Pan) que sus edades estuvieran comprendidas entre los 7 y los 12 años. El motivo de limitar el rango de edad a los 12 años fue que los niños, a partir de esa edad, ya se pueden considerar adolescentes. En cuanto a los 7, se encontró que, por debajo, los niños apenas sabían leer y tenían dificultades para expresar sus opiniones acerca de temas complejos como la discapacidad. La muestra resultante fue de 100 niños y niñas de entre 7 y 12 años (Tabla 1) de los cuales el 47\% eran niños y el $53 \%$, niñas.

Tabla 1. Sexo y edad de la muestra.

\begin{tabular}{|c|c|c|c|c|c|c|}
\hline Edades & 7 & 8 & 9 & 10 & 11 & 12 \\
\hline Niños & 8 & 8 & 8 & 6 & 9 & 8 \\
\hline Niñas & 8 & 10 & 10 & 6 & 8 & 11 \\
\hline
\end{tabular}

En tercer lugar, se elaboró el siguiente cuestionario, compuesto por una serie de preguntas cerradas que atienden a diversos aspectos del pirata protagonista estrechamente relacionados con las variables de las hipótesis.

P1: ¿Quiere vengarse de Peter Pan?

P2: ¿Notas en sus palabras su deseo de venganza?

P3: ¿Las palabras que utiliza Garfio son amables?

P4: ¿Sus palabras demuestran su enfado y su odio?

P5: ¿Crees que odia a Peter Pan porque le cortó la mano? 
P6: ¿Garfio es un personaje bueno?

P7: ¿Te parece un hombre malvado?

P8: ¿Sus gestos y sus tonos de voz reflejan (casi siempre) que está enfadado?

P9: ¿Garfio se arrepiente de hacer el mal?

P10: ¿Es la discapacidad lo que hace malvado a Garfio?

P11: ¿Crees que Garfio da mucho miedo?

P12: ¿El resto de personajes temen al capitán pirata?

P13: ¿Algunas escenas de Garfio son graciosas?

P14: ¿Los demás personajes se burlan del pirata protagonista?

P15: ¿Garfio merece terminar mal en la película?

La elección de preguntas cerradas (cuyas respuestas constituyen una escala Likert, como se puede apreciar a continuación) se produjo con el fin de facilitar la labor de los niños y para poder cuantificar sus respuestas con mayor rigor.

Las opciones de respuesta de la escala Likert utilizada son:

1. Completamente en desacuerdo

2. En desacuerdo

3. Ni de acuerdo ni en desacuerdo

4. De acuerdo

5. Completamente de acuerdo

Antes de enviar todas las encuestas, se llevó a cabo un pretest con veinte niños para confirmar que las preguntas se entendían y para averiguar si las hipótesis se iban cumpliendo.

Con el objeto de medir los resultados finales, se utilizó la metodología cuantitativa. Para garantizar la fiabilidad del instrumento empleado, se escogió el coeficiente alfa de Cronbach como método de consistencia interna.

Fórmula del coeficiente alfa de Cronbach

$$
\alpha=\frac{k}{k-1}\left[1-\frac{\sum S_{i}^{2}}{S_{T}^{2}}\right]
$$


Así, teniendo en cuenta los resultados de la encuesta (Tabla 5 en Resultados), se procedió a calcular dicho coeficiente a partir de las varianzas de los ítems (Tabla 2 y Tabla 3).

Tabla 2. Media y varianza por cada pregunta del cuestionario.

\begin{tabular}{|ccc|}
\hline Preguntas & Media & Varianza individual \\
\hline P1 & 5 & 0 \\
P2 & 5 & 0 \\
P3 & 5 & 0 \\
P4 & 5 & 0 \\
P5 & 4.77 & 0.74 \\
P6 & 5 & 0 \\
P7 & 5 & 0 \\
P8 & 4.85 & 0.43 \\
P9 & 5 & 0 \\
P10 & 4.74 & 0.8 \\
P11 & 4.79 & 0.59 \\
P12 & 4.70 & 0.82 \\
P13 & 4.94 & 0.18 \\
P14 & 4.85 & 0.43 \\
P15 & 4.68 & 1.10 \\
& & 5.09 \\
\hline
\end{tabular}

Dividiendo el sumatorio de la tercera columna entre 99 (n-1) como indica la fórmula de la varianza, se obtuvo una varianza total $\left(\mathrm{S}_{\mathrm{T}}{ }^{2}\right)$ de 26.57. Con todos los datos necesarios, se procedió a calcular el coeficiente alfa de Cronbach para medir la fiabilidad del instrumento de medición seleccionado. El resultado obtenido fue 0.87. Puesto que el instrumento se considera fiable si el valor se encuentra entre 0.7 y 0.9 (y es más fiable cuanto más se acerca a 1), el valor 0.87 indica que el cuestionario repartido a la muestra es adecuado. 
Tabla 3. Puntuación otorgada al cuestionario y primera operación para el cálculo de la varianza total.

\begin{tabular}{|c|c|c|}
\hline Número de niños & Puntuación total otorgada & $\left(\overline{\mathbf{x}}-\mathbf{x}_{\mathbf{i}}\right)^{\mathbf{2}}$ \\
\hline 90 & 6750 & 253.80 \\
\hline 2 & 72 & 3.48 \\
\hline 1 & 65 & 69.22 \\
\hline 1 & 60 & 177.42 \\
\hline 1 & 59 & 205.06 \\
\hline 2 & 53 & 825.80 \\
\hline 1 & 52 & 454.54 \\
\hline 2 & 48 & 641.10 \\
\hline & $\sum$ (puntuación total) $=7332$ & $\sum\left(\overline{\mathrm{x}}-\mathrm{x}_{\mathrm{i}}\right)^{2}=2630.42$ \\
\hline
\end{tabular}

Fuente: Elaboración propia.

\section{Resultados}

\subsection{Análisis}

Peter Pan es el decimocuarto clásico de la compañía Walt Disney. En el filme, el capitán Garfio, enemigo del niño que no quería crecer, se muestra como un ser vil y sanguinario al que no le importa hacer el mal. Bajo el prisma de la comunicación verbal y no verbal, los rasgos del personaje ofrecen datos que ayudan a probar las hipótesis y a definir al pirata.

Para dar respuesta a la hipótesis general [Disney recrea a Garfio como un Vengador Obsesivo a través de la comunicación verbal y no verbal], se han establecido cuatro variables. Por cada una de ellas, se han encontrado varias referencias en la realidad fílmica. La primera variable es la siguiente: Disney retrata a su pirata protagonista como un Vengador Obsesivo a través de palabras que demuestran su sed de venganza. La transcripción proporciona tres tipos de enunciados al respecto: deseos, planes y frases que Garfio dice directamente a Peter Pan. Los deseos son oraciones que el pirata emite en alto y que entran en relación con su espera y su ansia por atrapar a su enemigo. "Si yo pudiera encontrar su escondite, le echaría el guante" forma parte de ese grupo de oraciones ( 3 en el texto) con las que Garfio expresa su anhelo por culminar su venganza. En cuanto a los planes (6 en el texto), Garfio se pone en marcha para lograr su objetivo. En la escena en que el pirata se dispone a dejar una bomba en el escondite de Peter Pan, se puede oírlo decir Y ahora, Smee, atenderemos al amigo Peter Pan. También en algún momento (en 4 concretamente) Garfio emite frases que recibe directamente su rival: "Me las pagarás todas, Pan, aunque sea lo último que haga". Todas ellas aluden a la venganza que el capitán pirata espera acometer desde hace tanto tiempo. 
La segunda variable hace referencia al resto del discurso del personaje: Garfio cumple el estereotipo del Vengador Obsesivo porque su discurso está teñido de ira, crueldad, mentira, amargura y odio. Prácticamente la totalidad de lo que expresa Garfio con palabras tiene una clara connotación negativa. En sus intervenciones, se pueden apreciar (número - ejemplo): insultos (10- “Cómo puedes ser tan imbécil?”), maldiciones (4- “Malaya Peter Pan!”), amenazas (6- "Más vale que hables ya, querida, porque pronto subirá la marea y las aguas te cubrirán”), mentiras o falsedades (27- "Y por eso te he suplicado, querida, que le digas a Peter que no tengo nada contra él"), chantajes (2- "He aquí lo que yo te propongo: tú me dices dónde está el escondite de Peter Pan y yo te devuelvo tu libertad"), burlas (16- "Ya estoy viendo a nuestro amigo en estos momentos leyendo la cariñosa misiva"), órdenes despóticas (13- "Usted irá hasta la isla, captura a Campanilla y me la trae aquí a mí") y comentarios destructivos (23- "Los mataremos como a blancas palomitas").

Dejando a un lado las palabras, la tercera variable se refiere a la comunicación no verbal: El comportamiento (gestos, posturas, expresiones faciales, tonos de voz...) del enemigo de Peter Pan refleja a un ser malvado, iracundo y violento. En este punto, es preciso hacer una distinción entre sus ámbitos. Como indica Cestero (2006: 59), "el paralenguaje, la quinésica, la proxémica y la cronémica son los cuatro sistemas de comunicación no verbal reconocidos hasta el momento". En este caso, se abordan los tres primeros, pues la cronémica no es lo suficientemente relevante en este estudio.

Comenzando por la quinésica, los gestos, las posturas y las expresiones faciales significativos de Garfio que descubren su maldad suman 73 (de los que 36 son gestos, 3 son posturas y 34 son expresiones faciales). Garfio realiza con mucha frecuencia el gesto de alzar el garfio de forma amenazante (hasta 10 veces en la película). Pero no solo emplea el garfio para intimidar y amenazar a otros personajes; tras la escena de su afeitado frustrado, el capitán amenaza a Smee levantando su puño derecho muy cerca del rostro de su primer oficial. Otros gestos del pirata protagonista indican: ira (8), maldad (7), burla (4), satisfacción y disfrute frente al mal ajeno (14) y falsedad (4). A pesar de que todos los gestos podrían agruparse bajo el sustantivo "maldad", algunos de ellos demuestran puramente este concepto, sin mezclarse por entero con la rabia, la burla o el gozo. Las expresiones faciales de Garfio pueden clasificarse, también, en cinco de las categorías anteriormente mencionadas. La ira (9), la maldad (4), la burla (3), el disfrute por el mal ajeno (14) y la falsedad (4) están presentes en su semblante durante todo el filme. Cuando Tigrilla, la hija del jefe indio, se niega a desvelarle el lugar donde se esconde Peter Pan, Garfio se pone (literalmente) rojo de ira. En cuanto a su postura, en algunas escenas se aprecia cómo la cabeza de Garfio se adelanta a su cuerpo, lo que le otorga un aspecto más extraño y malvado. Esto enlaza directamente con la proxémica, pues Garfio se aproxima a sus interlocutores en 6 ocasiones con el fin de intimidarlos o amenazarlos. Ya en su primera intervención en la cinta, al sugerirle Smee que ha de controlar sus modales, Garfio se acerca a él, lo acorrala y se le echa encima bruscamente. Con respecto a la paralingüística, se ha realizado una nueva clasificación en la que se distinguen los tonos de voz, el volumen y todos los demás sonidos que emite Garfio y que insinúan a su maldad. Nuevamente, la ira (13), la falsedad (7), la mofa (1) y la satisfacción o el entusiasmo al contemplar o simplemente pensar en el mal (5) aparecen en su tono de voz, que 
también muestra, en una ocasión, indiferencia (1). Además, Garfio levanta la voz en 13 ocasiones (las mismas en las que el tono revela su ira) y se ríe de forma maliciosa hasta 5 veces.

En la cuarta variable, Garfio actúa sin compasión y sin remordimientos, se observan las acciones que este lleva a cabo. La empatía no es una cualidad del pirata protagonista de Peter Pan, que no solo no se pone en el lugar de aquellos a quienes insulta, amenaza o agrede, sino que ni siente pena ni se arrepiente de lo que hace en ningún momento. Tanto en la escena en que Garfio deja a Tigrilla en el mar, sobre una roca y atada a un ancla para que se ahogue si no le desvela cuál es el escondite de Peter Pan, como en la que Garfio dispara a un pirata y continúa con la conversación que estaba manteniendo como si no hubiera sucedido nada, se puede apreciar una falta absoluta de compasión y de remordimientos. Este tipo de acciones (24 en la película) recae sobre todos los demás personajes, sin importar si son niños o adultos; tanto los miembros de la tripulación (encabezada por Smee, que sufre la cólera de Garfio en varias escenas en las que es levantado del suelo y tirado después sobre este sin cuidado alguno) como Wendy (a quien manda tirarse al mar en presencia de sus hermanos), Juan, Miguel, los Niños Perdidos y, por supuesto, Peter Pan son víctimas de la furia imparable del capitán.

El estudio de las cuatro variables de la hipótesis principal permite llegar a la conclusión de que las oraciones (comunicación verbal) que presentan a Garfio como un ser cruel, iracundo y violento (en definitiva, como un Vengador Obsesivo) son 114, los elementos de la comunicación no verbal extraídos del análisis ascienden a 124, y, por último, las acciones suman 24. De este modo, se puede afirmar que los aspectos relacionados con la comunicación no verbal (seguidos muy de cerca por las palabras que emplea el pirata protagonista) alcanzan el mayor grado de presencia en el filme en comparación con el resto de rasgos analizados. Las acciones, instrumento que guía en muchas ocasiones las decisiones intuitivas en cuanto a la clasificación y categorización de los personajes, constituyen menos del 20\% de los rasgos no verbales que se muestran. Tomando todos los aspectos en conjunto (262), se obtendrían los siguientes porcentajes en cuanto a su presencia en la cinta cinematográfica: comunicación verbal (43.5\%), comunicación no verbal (47.3\%) y acciones (9.2\%).

La segunda hipótesis, por su parte, se formula así: Garfio no es el prototipo de villano, pues algunos rasgos de su personalidad hacen que no infunda temor y proporcionan al personaje una vis cómica. La primera variable de esta hipótesis específica es que el pirata es un personaje torpe, cobarde y con mala suerte cuyas malas acciones se vuelven contra él. Su torpeza se ve reflejada en 4 ocasiones; entre ellas, su fallida caída al vacío en plena lucha en la Roca Calavera. En un instante, Garfio se da cuenta de que no hay tierra firme bajo sus pies y acaba colgado de un saliente por el garfio. En cuanto a su cobardía, entre las 7 escenas que se encuentran en la película destacan aquellas en las que el pirata muestra su temor hacia uno de sus grandes enemigos: el cocodrilo. Así, cuando aparece el animal la primera vez, Garfio implora, temeroso, “¡Smee, sálvame, por favor, no dejes que me coma! ¡Dile que se vaya!”. Con respecto a la mala suerte, también en 7 ocasiones puede comprobarse que Garfio no es muy afortunado y que sus propias acciones se vuelven contra él. Helado, abatido y dolorido tras huir del cocodrilo, Garfio sale (de su camarote) a quejarse del ruido que escucha con expresión furibunda y se 
lleva accidentalmente un martillazo del Señor Smee. Paradójicamente, el ruido que oía procedía de los golpes que Smee daba con el martillo al colgar un cartel que reza "Silencio. No molestar"; esta es, pues, una buena muestra de que el villano no tiene suerte y con frecuencia recibe su merecido.

A continuación, se muestra una tabla que resume las características apreciables en la figura del capitán Garfio correspondientes a la hipótesis principal:

Tabla 4. Rasgos verbales y no verbales del capitán Garfio.

\begin{tabular}{|l|l|c|c|}
\hline Aspectos analizados & Rasgos de Garfio & $\begin{array}{c}\text { Número de } \\
\text { veces }\end{array}$ & Porcentajes \\
\hline $\begin{array}{l}\text { Comunicación } \\
\text { verbal }\end{array}$ & Deseo de venganza & 13 & $4.96 \%$ \\
\cline { 2 - 4 } & $\begin{array}{l}\text { Resto de enunciados } \\
\text { (insultos, maldiciones, } \\
\text { amenazas...) }\end{array}$ & 101 & $38.55 \%$ \\
\hline $\begin{array}{l}\text { Comunicación no } \\
\text { verbal }\end{array}$ & $\begin{array}{l}\text { Quinésica (ira, } \\
\text { maldad, burla...) }\end{array}$ & 73 & $27.86 \%$ \\
\cline { 2 - 4 } & $\begin{array}{l}\text { Proxémica } \\
\text { (intimidación, } \\
\text { amenaza) }\end{array}$ & 6 & $2.29 \%$ \\
\cline { 2 - 4 } & $\begin{array}{l}\text { Paralingüística } \\
\text { (ira, indiferencia, } \\
\text { falsedad...) }\end{array}$ & 45 & $17.18 \%$ \\
\hline Acciones & $\begin{array}{l}\text { Sin compasión y sin } \\
\text { remordimientos }\end{array}$ & 24 & $9.16 \%$ \\
\hline
\end{tabular}

Fuente: Elaboración propia.

La segunda variable de la hipótesis específica atiende a las palabras, los gestos y las acciones correspondientes a los demás personajes, pero relacionados con el capitán Garfio; apunta, por ende, a las reacciones que este provoca. Los aspectos citados desvelan que ni la tripulación ni los niños temen al pirata protagonista. En alguna ocasión, Smee sugiere a Garfio lo que debería hacer ("durante el afeitado") o demuestra que no está de acuerdo con sus órdenes (al subir a Tigrilla al bote para devolvérsela a su padre). Además, al principio de la cinta, se aprecia, también, que la tripulación no acata las órdenes de su capitán sin rechistar, y queda claro que Garfio no representa una autoridad para los piratas, que se atreven a expresar sus propias opiniones (contrarias a las del capitán) sin temor a represalias. La oración "Dile al Capitán Garfio que queremos volver a la mar", que uno de los piratas espeta a Smee de malos modos, aúna el criterio del conjunto de los miembros de la tripulación. Del mismo modo que no lo temen ni respetan sus órdenes y sus decisiones, en varias escenas se aventuran, incluso, a burlarse de él (algo que hace también Peter Pan constantemente). De hecho, durante la primera escena que tiene lugar en el barco, varios piratas lanzan cuchillos tomando como diana la puerta del camarote de Garfio, en la que han 
dibujado una caricatura del capitán. Y, en mitad de la última lucha, Peter Pan le hunde el sombrero roto en la cabeza a Garfio y le corta la pluma, llevándosela triunfal.

\subsection{Encuestas}

De las encuestas realizadas por la muestra se extraen los resultados relativos a la percepción de Garfio por parte de los niños (Tabla 5), que confirman lo que se observa en el filme.

Tabla 5. Número de niños que opta por cada respuesta para cada pregunta del cuestionario.

\begin{tabular}{|c|c|c|c|c|c|}
\hline & $\begin{array}{l}\text { Completamente } \\
\text { en desacuerdo }\end{array}$ & $\begin{array}{c}\text { En } \\
\text { desacuerdo }\end{array}$ & $\begin{array}{l}\text { Ni de acuerdo ni } \\
\text { en desacuerdo }\end{array}$ & De acuerdo & $\begin{array}{c}\text { Completamente } \\
\text { de acuerdo }\end{array}$ \\
\hline P1 & & & & & 100 \\
\hline P2 & & & & & 100 \\
\hline P3* & 100 & & & & \\
\hline P4 & & & & & 100 \\
\hline P5 & 3 & 3 & 1 & & 93 \\
\hline P6* & 100 & & & & \\
\hline P7 & & & & & 100 \\
\hline P8 & & 5 & & & 95 \\
\hline P9* & 100 & & & & \\
\hline P10* & 92 & & & 6 & 2 \\
\hline P11* & 93 & & & 7 & \\
\hline P12* & 90 & & & 10 & \\
\hline P13 & & 2 & & & 98 \\
\hline P14 & & 5 & & & 95 \\
\hline P15 & 8 & & & & 92 \\
\hline
\end{tabular}

Fuente: Elaboración propia. 
*Las preguntas marcadas con un asterisco están formuladas de manera inversa para evitar una posible tendencia de los encuestados a la aquiescencia, por lo que han sido recodificadas posteriormente.

\section{Discusión}

El cine es un medio de gran utilidad, una herramienta de transmisión de ideas (Aparicio \& Gómez-Vela, 2010; Arroio, 2010) que posee, entre sus funciones, la de formar a los espectadores (Monjas \& Arranz, 2010). Una de las particularidades más relevantes del séptimo arte es que esta función, a veces, pasa inadvertida; tanto, que habitualmente no nos damos cuenta de que existe. Este aspecto hace del cine un arma de doble filo. Por un lado, posee la facultad de educar, de enseñar (Martín, 2016; Llinares, 2008; Martínez-Salanova, 2003; Cabero, 2003; Alonso \& Pereira, 2000); por otro, al no transmitir siempre la realidad tal y como es, se arriesga a que el público asuma como ciertas cosas que no lo son.

Los niños entienden las películas como una mera forma de entretenimiento, sin percatarse de que todo lo que perciben queda grabado en el subconsciente (McAlpine, 2011; Ocaña \& Reyes, 2010; Laury, 2009; Lipton, 2008). Los más pequeños, que aún no cuentan con la suficiente madurez y, por tanto, carecen de un criterio formado, aceptan como realidad lo que perciben a través de los filmes. Esto sucede, en mayor medida, con aquello que desconocen (puede ser este el caso de la discapacidad). Por esta razón, resulta fundamental, no solo encontrar y señalar el estereotipo cuando aparezca, sino averiguar qué elementos (ajenos a la discapacidad) captan los niños y que son los que verdaderamente lo definen.

En el caso del capitán Garfio, como se ha podido apreciar tanto en el análisis como en la encuesta realizada por la muestra, su carácter se percibe a través de sus palabras, sus gestos, sus tonos de voz, sus expresiones faciales... y sus acciones. Aunque ejercen su papel, estas últimas no son los únicos aspectos que lo definen; se hace preciso recurrir a los elementos de la comunicación verbal y la comunicación no verbal para aseverar que el pirata se presenta como un Vengador Obsesivo.

El análisis descriptivo muestra que existe una predominancia de los rasgos propios de la comunicación no verbal, esencial "para comunicar a los demás lo que a veces puede que sea sencillamente inefable" (Poyatos, 1994: 20). Los gritos, las caras de furia, los tonos de enfado y los gestos amenazantes del pirata son lo más significativo para la mayoría de los niños. Las palabras también gozan de una relevancia que debemos destacar. Es importante subrayar que la película, estrenada en 1953, ha tenido durante muchos años un público cuyos procesos mentales difieren de los que caracterizan a los niños en la actualidad. La enorme oferta tecnológica a su disposición marca una diferencia sustancial, pues los niños viven rodeados de imágenes (Arizpe \& Styles, 2002) y, en ese nuevo universo que ya es una realidad, las palabras pasan a un segundo plano.

La parte visual avanza cada vez más en detrimento de lo verbal. De Miguel (2003: 51) apuntaba hace años que "lo que no se ve apenas se piensa, tampoco se categoriza". Los niños que componen la muestra no tienen ninguna duda de que las palabras de Garfio demuestran su sed de venganza (algo que confirma el análisis fílmico). Tampoco dudan al responder que las palabras emitidas por el enemigo de 
Peter Pan no resultan amables. No obstante, habría sido más difícil pedirles que percibieran la mentira, el chantaje o el despotismo. Sí encontramos, a pesar de ello, en el análisis, ejemplos de este tipo de enunciados, que, sumados a los demás (insultos, maldiciones, amenazas, burlas y comentarios destructivos), confieren al discurso del personaje la carga negativa (ira, crueldad, mentira, amargura y odio) que se proponía. Si bien no todas las categorías de palabras son significativas para percibir a Garfio como un Vengador Obsesivo, el conjunto muestra signos inequívocos de que se ajusta al patrón.

Independientemente de la importancia que se ha de conceder a las palabras, el número de momentos en Peter Pan en que atendemos a la comunicación no verbal es claramente superior, lo que nos lleva a recordar que, como indicaba Flora Davis (1976: 52), "el cuerpo es el mensaje". La comunicación no verbal influye en gran medida en el modo en que percibimos los mensajes, ya que posee una fuerza y una capacidad de transmisión de emociones indiscutibles (Albaladejo, 2008; López, 2011; García, 1991; Gross, Crane \& Fredrickson, 2010). En efecto, tan solo el volumen y el tono de voz del capitán Garfio o sus expresiones faciales son un gran indicativo de su sentimiento de amargura y de sus deseos malvados.

La hipótesis general queda respaldada tanto por el análisis como por las respuestas de los niños, que demuestran que hay consenso. Tan solo unas pocas preguntas provocan que alguno de los integrantes de la muestra se aleje de este. Ante la negativa a si los gestos y tonos de Garfio reflejan su enfado (cinco niños), se puede suponer que el recuerdo del personaje se encuentra un poco difuminado; en cuanto a la afirmación de que es la discapacidad lo que hace malo al capitán pirata (ocho niños), el desconocimiento de una realidad compleja a una edad tan temprana es habitual y hasta puede ser comprensible. Tan solo siete niños opinan que Garfio no odia a Peter Pan porque le cortó la mano, lo que plantea una pregunta necesaria: ¿lo odia? Si la respuesta es afirmativa, ¿por qué si no es porque le cortó la mano? Pese a estas respuestas, todos están de acuerdo en que el pirata quiere vengarse y en que este deseo se aprecia en sus palabras.

En lo que respecta a la hipótesis específica, el análisis de la película ofrece evidencias suficientes de la vis cómica del pirata protagonista y deja claro que este no puede ser categorizado como un villano temible que amedrenta a los personajes y a los espectadores. Sin embargo, esta segunda hipótesis proporciona un mayor contraste entre dicho análisis y las respuestas de la muestra.

Aunque no hay diferencias significativas entre las respuestas de los niños y las de las niñas en el resto de las preguntas, llama la atención que solo dos niñas opinen que Garfio da miedo frente a los cinco niños que hacen lo propio. Es curioso, además, que no sean solo los miembros más pequeños del estudio quienes opten por afirmar esto, lo que permite averiguar que algunos niños tienen muy interiorizado el concepto de que los personajes malvados necesariamente han de dar miedo. Sí se debe recalcar que ninguno de los niños y niñas de 12 años (quizá con una percepción más amplia de lo que les rodea y, en este caso, del personaje y las reacciones que suscita) ha optado por la respuesta afirmativa.

Nos topamos con la paradoja en la siguiente pregunta, pues hasta diez niños perciben que los demás personajes de la cinta temen al capitán pirata. Sin embargo, algunos de estos han contestado que no da miedo. No entrañan una gran relevancia 
las dos únicas negativas a la existencia de escenas graciosas relacionadas con el personaje. Sí resulta curioso, por su parte, que sean algunos de los integrantes mayores los que no aprecian la burla. Ante esto, es posible cuestionarse si no son capaces de percibirla o si no se acuerdan. Por último, no creen que merece acabar mal ocho miembros. ¿Son partidarios de que merece una segunda oportunidad o participan de un buenismo exagerado?

Dada la gran cantidad de información que proporcionan, se hace necesario atender a los procesos de la comunicación verbal y no verbal en las películas infantiles. Es imprescindible cuidar las palabras y construir personajes alejados de los estereotipos, cuyas buenas o malas acciones, expresiones faciales o gestos nada tengan que ver con la discapacidad. Se ha de aprovechar, asimismo, la idea de material de ocio y diversión que los niños otorgan al cine (Monjas \& Arranz, 2010: 55) para intentar inculcar valores positivos (Castillo, 2010; Bonilla, Loscertales \& Páez, 2012) y enseñar realidades de manera acertada, cumpliendo así con la labor de formar.

Cierto es que el cine ha empleado la discapacidad de forma errónea en múltiples ocasiones, creando estereotipos que se asumían por sus marcadas características y la repetición en su uso. Sin embargo, incluso los más pequeños son capaces de defender, con sus opiniones, que la discapacidad y la maldad no tienen vinculación alguna.

\section{Referencias bibliográficas}

Alegre, O. M. (2003). La discapacidad en el cine. Barcelona: Octaedro.

Albaladejo, M. (2008). La comunicación no verbal en el aula. Padres y Maestros, 314, 9-13.

Alonso, M. L., y Pereira, M. C. (2000). El cine como medio-recurso para la educación en valores: Un enfoque teórico y tecnológico. Pedagogía Social, 5, 127-147. Aparicio, D., y Gómez-Vela, M. (2010). De criados mudos, jóvenes sordas y otros estereotipos: Las personas con problemas de audición y lenguaje en el cine. Revista de Medicina y Cine, 6(2), 47-54.

Aparicio, D., y Jordán de Urríes, B. (Coords.). (2014). Dosier Cine y Discapacidad. Arizpe, E., y Styles, M. (2002). ¿Cómo se lee una imagen?: El desarrollo de la capacidad visual y la lectura mediante libros ilustrados. Lectura y Vida, 23(1), 20-29.

Arroio, A. (2010). Context Based Learning: A Role for Cinema in Science Education. Science Education International, 21(3), 131-143.

Badia, M. (2010). La imagen de la discapacidad en el cine: ¿Rompiendo estereotipos? Revista de Medicina y Cine, 6(2), 38-39.

Badia, M., y Sánchez-Guijo, F. (2010). La representación de las personas con discapacidad visual en el cine. Revista de Medicina y Cine, 6(2), 69-77.

Black, R. S., y Pretes, L. (2007). Victims and Victors: Representation of Physical Disability on the Silver Screen. Sage, 32(1), 66-83. doi: https://doi.org/10.2511/ rpsd.32.1.66 
Bonilla, J., Loscertales, F., y Páez, M. M. (2012). Educación en valores a través del cine. Pixel-Bit, 41, 117-131.

Cabero, J. (2003). Educación en valores y cine. Making of. Cuadernos de Cine y Educación, 20, 16-30.

Castillo, M. A. (2010). El cine y la educación en valores. Publicaciones Didácticas, $3,51-58$.

Cestero, A. M. (2006). La comunicación no verbal y el estudio de su incidencia en fenómenos discursivos como la ironía. ELUA, 20, 57-77. doi: https://doi. org/10.14198/ELUA2006.20.03

Chacón, A. (2005). La infancia ante los nuevos medios: La televisión. Etic@net, II(4), 65-84.

Davis, F. (1976/1996). Comunicación no verbal (22. ${ }^{a}$ Reimpresión). Madrid: Alianza Editorial.

De Miguel, J. M. (2003). El ojo sociológico. Revista Española de Investigaciones Sociológicas, 101, 49-88.

Disney, W. (productor), Geronimi, C., Jackson, W., y Luske, H. (directores). (1953). Peter Pan [DVD]. Estados Unidos: Walt Disney Pictures.

García, J. L. (1991). La comunicación de las emociones. (Tesis doctoral). Universidad Complutense, Facultad de Ciencias de la Información, España.

Gross, M. M., Crane, E. A., y Fredrickson, B. L. (2010). Methodology for Assessing Bodily Expression of Emotion. Journal of Nonverbal Behavior, 34(4), 223-248. doi: https://doi.org/10.1007/s10919-010-0094-X

Laury, J. (2009). Children Are Little Mirrors. Estados Unidos: Xlibris.

Lipton, B. H. (2008). The Power of the Mind. New Dawn.

Llinares, J. J. (2008). Frases de cine. Madrid: Vision Libros.

Longmore, P. K. (2003). Why I Burned My Book and Other Essays on Disability. Philadelphia: Temple University.

López, R. M. (2011). Club del Lenguaje no verbal.

Martín, E. (2016). El cine como estrategia didáctica para combatir actitudes racistas y xenófobas entre el alumnado de ESO. Sevilla: Punto Rojo Libros.

Martínez-Salanova, E. (2003). El valor del cine para aprender y enseñar. Comunicar, $X(20), 45-52$.

McAlpine, R. (2011). Inspired Children: How the Leading Minds of Today Raise Their Kids. Sydney: Darlington Press.

Monjas, M. I., Arranz, F., y Rueda, E. (2005). Las personas con discapacidad en el cine. Siglo Cero, 36(1), 13-29.

Monjas, M. I., y Arranz, F. (2010). El cine como recurso para el conocimiento de las personas con discapacidad: Veinticinco películas de la última década. Revista de Medicina y Cine, 6(2), 55-68.

Norden, M. F. (1998). El cine del aislamiento: El discapacitado en la historia del cine. Madrid: Escuela Libre Editorial - Fundación ONCE.

Norden, M.F. (2007). The Changing Face of Evil in Film and Television. Ámsterdam: Rodopi.

Norden, M. F. (2014). American Narrative Films and Disability: An Uneasy History. En T. Jones, D. Wear, y L. D. Friedman (Eds.), Health Humanities Reader (pp. 87-96). New Brunswick, NJ: Rutgers University Press. 
Ocaña, A., y Reyes, M. L. (2010). El imaginario sonoro de la población infantil andaluza: Análisis musical de La Banda. Comunicar, XVIII(35), 193-200. doi: https://doi.org/10.3916/C35-2010-03-13

Poyatos, F. (1994). La comunicación no verbal I: Cultura, lenguaje y conversación. Madrid: Istmo.

Sanz, L. (2014). Cine y discapacidad. En F. Vilches, y L. Sanz (Coords.), Comunicación social y accesibilidad (pp. 195-261). Madrid: Dykinson.

Solaz, L. (2004). La parada de los monstruos: Tod Browning (1932). Barcelona: Octaedro.

Sutton, T. (2014). Avenging the Body: Disability in the Horror Film. En H. M. Benshoff (Ed.), A Companion to the Horror Film (pp. 73-89). Sussex Occidental, Reino Unido: Wiley Blackwell. 